Etnográfica

Revista do Centro em Rede de Investigação em

Antropologia

vol. $16(1) \mid 2012$

Vol. $16(1)$

\title{
O paradoxo dos prazeres: trabalho, homossexualidade e estilos de ser homem no candomblé queto fluminense
}

The paradox of pleasure: work, homosexuality and styles of being a man in an Afro-Brazilian religious nation in Rio de Janeiro

\section{Luís Felipe Rios}

\section{(2) OpenEdition}

\section{Journals}

\section{Edição electrónica}

URL: https://journals.openedition.org/etnografica/1382

DOI: 10.4000/etnografica.1382

ISSN: 2182-2891

\section{Editora}

Centro em Rede de Investigação em Antropologia

\section{Edição impressa}

Data de publição: 1 fevereiro 2012

Paginação: 53-74

ISSN: 0873-6561

\section{Refêrencia eletrónica}

Luís Felipe Rios, «O paradoxo dos prazeres: trabalho, homossexualidade e estilos de ser homem no candomblé queto fluminense», Etnográfica [Online], vol. 16 (1) | 2012, posto online no dia 23 março 2012, consultado o 10 fevereiro 2022. URL: http://journals.openedition.org/etnografica/1382 ; DOI: https://doi.org/10.4000/etnografica.1382

\section{(c) (†) 8}

Etnográfica is licensed under a Creative Commons Attribution-NonCommercial 4.0 International License. 


\section{O paradoxo dos prazeres: trabalho, homossexualidade e estilos de ser homem no candomblé queto fluminense}

\section{Luís Felipe Rios}

Este artigo analisa a inserção de homens com práticas homossexuais no candomblé queto fluminense. Nesses candomblés, as articulações entre performances de gênero e trabalho religioso constituem estilos de ser homem, que configuram uma hierarquia sexual. Os masculinizados (okós) podem assumir posições de mediação terreiro-mundo, o que não é permitido aos efeminados (adés). Com gestualidade e adereços, eles sinalizam os gostos sexuais, e cria-se um paradoxo: se apresentar a um só tempo masculino e feminino, de modo a ser respeitado pelo grupo e sinalizar quem e o que quer sexualmente.

PALAVRAS-CHAVE: gênero, trabalho, religiões afro-brasileiras, homossexualidade masculina, discriminação.

The paradox of pleasure: work, homosexuality and styles of being a man in an Afro-Brazilian religious nation in Rio de Janeiro - The article analyzes the insertion of men with homosexual practices in an Afro-Brazilian religious nation in Rio de Janeiro Candomblé. In this religion, the articulations between gender performances and religious work constitute styles of being a man, configuring a sexual hierarchy. It is argued that mediating positions between temple and world can be assumed by the mannish men (okós), but are not permitted to the effeminates (adés). As sexual tastes are signalized by gestures and props, a paradox is created to homosexual men: to present themselves, at the same time, mannish and feminine in order to be respected by the community, and yet clearly show who and what they want sexually.

KEYwORDS: gender, work, African-Brazilian religions, male homosexuality, discrimination.

RIOS, Luís Felipe (Ifelipe.rios@gmail.com) - Universidade Federal de Pernambuco, Brasil 
NESTE ARTIGO, REFLITO SOBRE OS SENTIDOS E OS VALORES RELATIVOS aos homens com práticas homossexuais nos terreiros de candomblé queto fluminenses. ${ }^{1}$ Os dados aqui analisados foram coligidos entre 2000 e 2004, no âmbito de uma pesquisa de base etnográfica viabilizada por observação participante, em casas de candomblé dos subúrbios do Rio de Janeiro e da Baixada Fluminense, e por entrevistas com seus frequentadores.

Investiguei os modos como jovens homens que fazem sexo com homens constituem parcerias e práticas sexuais, na perspectiva de contribuir para o entendimento do caminho da epidemia de AIDS, com especial destaque analítico às relações de poder associadas à sexualidade, que concorrem para torná-los vulneráveis ao HIV. Neste artigo, preocupo-me menos com as escolhas sexuais e com as práticas que têm espaço "entre quatro paredes", e mais com o modo como os homens são apreendidos no cotidiano pela economia política do sexo-gênero (Rubin 1993; Lancaster 1999), como constituída nos terreiros.

A literatura especializada apresenta os terreiros de candomblé como lugares homófilos (Landes 1967; Fry 1982, 2010; Teixeira 1987; Matory 1988; Birman 1995; Segato 1995), entretanto, nem sempre encontrei completa abertura às homossexualidades nos terreiros fluminenses. Deparei com um campo religioso plural, não só do ponto de vista cosmológico, mas também em relação à apreensão das homossexualidades. Ainda que todos os terreiros de candomblé aceitassem tacitamente a presença de pessoas com práticas homossexuais, constituíam-se de forma diferenciada os lugares a ser ocupados pelos homens nos terreiros, considerando-se o modo como eles reiteram no gênero seus gostos eróticos.

Sem deixar de circular em terreiros de diferentes denominações, realizei observação sistemática em dois terreiros de candomblé queto relacionados às casas consideradas tradicionais no campo afro-brasileiro e na academia. ${ }^{2}$ Ainda que sejam de terceira e quarta geração, os terreiros que pesquisei conseguem encontrar certo status no campo dominado pelas casas consideradas tradicionais; por isso, denomino-os emergentes. Neles, do mesmo modo que nas casas

I A pesquisa que originou este artigo teve financiamento do VI Programa de Metodologia de Pesquisa em Gênero, Sexualidade e Saúde Reprodutiva - Nepo/Unicamp - e bolsa de doutorado da Fundação de Apoio à Pesquisa do Estado do Rio de Janeiro. Meus agradecimentos ao prof. Richard Parker, orientador da tese cujos dados e análises possibilitaram este artigo, e também à prof. ${ }^{a}$ Lady Selma Albernaz, pela leitura e pelas sugestões incorporadas ao texto.

2 Entre os terreiros de candomblé queto fluminenses, as casas tradicionais são resultantes de um fluxo migratório de baianos, no início do século XX (Augras 1983). Seus sacerdotes estão diretamente relacionados aos terreiros baianos do Gantois, Engenho Velho, Alaquêto, Axé de Procópio de Ogunjá, etc. No caso do Axé Opô Afonjá, em que há casas do mesmo nome em Salvador e na Baixada Fluminense, há disputa de entendimento sobre qual terreiro foi fundado primeiro, depois que Mãe Aninha se desvinculou do Engenho Velho para dar início a sua própria linhagem. 
matrizes, há certa exigência para que os homens declaradamente homossexuais diminuam a visibilidade de suas posições sexuais por via de "coisas do feminino", em especial nos dias de festa pública. ${ }^{3}$ Entre os emergentes, o redobrado cuidado com as supracitadas performances de gênero pelos homens, aliado a um jogo de agências relacionado a sinais de senioridade (biológica e religiosa) das mulheres, busca emitir sentidos de tradicionalidade. Todos os esforços concorrem para se diferenciarem de outras linhagens de candomblé, em especial do efon, em que a feminilidade agenciada por homens é incentivada (Rios 2002).

A partir desse pano de fundo etnográfico, busco argumentar ao longo deste texto que, nos terreiros de candomblé queto, é a divisão do trabalho (religioso), em sua centralidade para organizar relações de gênero, que pede estilos apropriados de ser homem, para que estes assumam posições de destaque na hierarquia sacerdotal. Tais estilos são objeto de vigilância e controle dentro dos terreiros, uma vez que são avaliados pelas "visitas", e são um dos indicadores para que as casas matrizes e o campo mais amplo reconheçam as emergentes como portadoras de tradicionalidade.

Para a interpretação dos dados, guiei-me por uma perspectiva teórica que conceitua a sexualidade como construída culturalmente e na multivocalidade. Como sugere Rubin (1998), lógicas distintas, ainda que indissociáveis, podem ser utilizadas para constituir sentidos e valores sobre os acontecimentos sexuais. Seguindo essa perspectiva, Parker (1991) propôs que três grandes sistemas, pelo menos, podem ser analiticamente distinguidos para a compreensão da cultura sexual brasileira: as hierarquias de gênero, os dispositivos de sexualidade, a ideologia do erótico.

O sistema das hierarquias de gênero tende a operar a partir da reiteração performática de atributos concebidos como de masculinidade e de feminilidade, que, remetidos aos órgãos sexuais enfatizados em suas funções reprodutivas, afirmam uma bipolaridade humana, hierarquizando os seres em categorias politicamente assimétricas e sexualmente complementares (Rubin 1993; Butler 2003). Os dispositivos de sexualidade articulam as interações sexuais, a partir de discursos instituídos de verdade (ciência e religião, por exemplo), que dizem o que é certo e o que é errado nas interações sexuais, para a ordem do mundo (Rubin 1998). Já a ideologia do erótico apreende os fenômenos sexuais, enfocando os prazeres que os corpos podem oferecer aos sujeitos e, conforme Parker (1991), estaria calcada na subversão dos limites

3 Os ritos e modos de fazer são semelhantes nos terreiros tradicionais e emergentes, e é muito comum haver "visitas" ilustres nas casas matrizes, colaborando com os rituais mais secretos e as festas ou assistindo a eles. Há, então, uma espécie de avaliação pelos "mais velhos" do saber dos sacerdotes emergentes. Essa avaliação espalha-se no campo mais amplo pelo canal da fofoca, e interfere na atribuição de status aos emergentes (Rios 2002, 2004). 
impostos pelos sistemas de gênero e de sexualidade, recorrentemente evocados nas brincadeiras sobre o sexo.

Tomei esse modelo teórico como hipótese mais abrangente - ou como tipo ideal weberiano (Weber 1989) -, permitindo que, ao mesmo tempo em que orientasse meu caminho no processo de desvelar a cultura sexual dos terreiros, tal modelo pudesse ser redescrito e ampliado, a partir do momento em que não mais tivesse a capacidade de alargar a compreensão sobre as políticas sexuais e o modo como os homens com práticas homossexuais nelas se inserem.

Este artigo está organizado em quatro partes. Na primeira, apresento a organização social dos terreiros e exploro como o processo de reprodução sociocultural apreende as sexualidades. Na segunda, abordo o sistema erótico nos modos como os terreiros significam, em tom jocoso, as práticas sexuais. $\mathrm{Na}$ terceira parte, guiado pelo trajeto de um jovem em um dos terreiros estudados, retomo o sistema de gênero na interface com a hierarquia religiosa, de modo a refletir sobre as assimetrias de poder entre os homens, a partir do modo como eles articulam publicamente coisas do feminino. Na última parte, discuto o modo como o trabalho pede estilos apropriados de ser homem, para que se assumam posições de destaque na hierarquia sacerdotal.

\section{AXÉ E REPRODUÇÃO}

O candomblé é uma religião politeísta, na qual as divindades (orixás), relacionadas aos fenômenos naturais e patronas de atividades sociais, são temperamentais e muito humanas. Elas sentem desejos e têm fome, exigem como oferendas sacrifícios de animais e comidas diversas, tomam o corpo dos fiéis em momentos de festa e vêm bailar para a assistência.

Os centros religiosos viabilizam contatos favoráveis entre aiê (mundo) e orun (outro mundo), os quais se fazem por via da manipulação do axé (energia mística). Para tal, pessoas são iniciadas como sacerdotisas da religião e aprendem, com o galgar de uma hierarquia, os segredos e fundamentos para o serviço religioso. Uma metáfora familiar é utilizada para nomear a hierarquia: pai de santo ou mãe de santo, que se configura como sacerdote supremo e é auxiliado em seus serviços pelos filhos e filhas de santo.

As pessoas capazes de "virar" (entrar em transe) com o orixá são chamadas rodantes. Essa categoria tem duas subcategorias etárias: iaôs e ebômis. A iâ̂ (esposa mais nova) vai progredindo na hierarquia, juntamente com a realização das "obrigações" e dos rituais que confirmam a iniciação - ao fim de um, três e sete anos. Realizada a "obrigação de sete anos", a pessoa se torna ebômi (irmão mais velho). De iâ̂ a ebômi, a pessoa adquire status de pai ou mãe, e ganha alguns privilégios dentro da casa de santo.

Os/as não rodantes seguem outro caminho iniciático: são denominados ogãs (os homens) e equedes (as mulheres), são pessoas escolhidas pelos orixás para 
ser seus "pais" e "mães" no aiê, e cabe-lhes cuidar das divindades quando incorporadas nos rodantes. Ogãs e equedes não devem, portanto, ser capazes de possessão. Quando iniciados ("confirmados"), são tratados como "meu pai og ã" ou "minha mãe equede", e merecem as deferências devidas aos "mais velhos". Os ogãs são responsáveis pelo sacrifício dos animais e toque dos atabaques, e as equedes auxiliam os "santos" em suas atividades no aiê - secam-lhes o suor, ajudam-nos a se vestir e se paramentar, acompanham-nos na dança, etc.

Nos terreiros que estudei, ainda que homens e mulheres possam galgar os postos supremos, boa parte do trabalho religioso mais especializado é repartida por sexo. Por exemplo, apenas homens podem sacrificar, tocar atabaque e oficiar os rituais aos egunguns (ancestrais); já as mulheres "rodam" o Ipadê (ritual que convida os orixás para a festa pública), dirigem a cozinha sagrada e cultuam as iamis (feiticeiras sagradas), o que faz com que se torne sempre necessária a presença de homens e mulheres nos terreiros, de modo que os serviços religiosos se realizem.

É nesse contexto "familiar" que se deve pensar a reprodução (social) nos terreiros. Ainda que, em última instância, dependam da reprodução biológica, os nascimentos que importam aos sacerdotes são os de novas iaôs, que se fazem por via de procedimentos rituais (iniciação, chamada também de "feitura"). Isso não quer dizer que deixam de existir os discursos de verdade sobre a sexualidade, em suas implicações para a relação entre o mundo e o outro mundo, e sobre a continuidade da religião.

É justamente nessa conjuntura reprodutiva que a sexualidade volta a ser apreendida. A iniciação faz-se por via de rituais em que o axé, energia que transita entre aiê e orun, é manipulado. Para uma pessoa participar da feitura ou se submeter a ela, como a qualquer outro rito, deve abster-se de sexo, a fim de acumular a energia sagrada. A crença é que o axé se dissipa por meio da interação sexual, uma vez que ele tem nos fluidos corporais seus suportes. Assim, para o candomblé, o que importa são os momentos em que se pode ou não ter atividades sexuais. ${ }^{4}$

Segato (1995) atribui essa inflexão sobre a reprodução social nas comunidades-terreiro ao impacto do sistema escravista sobre a família escrava, que desordenou os sistemas de parentesco e de gênero tradicionais africanos e deslocou a centralidade da conjugalidade como lugar para vivência dos prazeres sexuais. Seriam essas mudanças nas premissas para a reprodução social (do biológico para o espiritual) que possibilitariam a abertura dos terreiros para as sexualidades que se organizam na margem da heteronorma. Nesse ínterim, a possibilidade de haver práticas sexuais entre pessoas do mesmo sexo existe e é,

4 Há interditos quanto às transações sexuais dentro da família de santo, os quais não tenho condições de aprofundar aqui (ver Segato 1995; Rios 2004). 
inclusive, legitimada pelos deuses. Por exemplo, Oxóssi, o caçador, patrono dos ogãs, teve sexo com Ossaim, o feiticeiro.

\section{QUANDO O AZEITE ESCORRE...}

Temáticas sexuais estão sempre na iminência de "incorporar" no disse me disse das "casas de santo". O "fazer sexo", ainda que fisicamente controlado por rígidas normas que relacionam o ato com o próprio cultivo do axé, é, discursivamente, elemento recorrente, faz parte da ludicidade que impregna o cotidiano. Para quem está chegando nesse universo, pode até parecer que essa prática livra das amarras impostas pela sexualidade reprodutiva e permite mergulhar preponderantemente na ordem do sistema erótico, como situado por Parker (1991). Excetuando-se os momentos rituais, a qualquer momento, "o azeite e a pimenta" podem "escorrer", e a conversa rumar para comentários sobre dotes ou impropriedades sexuais de alguém.

Nem as divindades são poupadas, e, acentuadas em suas características sexuais, são utilizadas para dar sentido às pessoas e situações do mundo. Elas metamorfoseiam o prazer sexual no prazer do humor. São recorrentes encenações em que homens e mulheres brincam com as coreografias da dança: os filhos de santo se deliciam em parodiar, por meio de alguns dos orixás, eventos da comunidade religiosa. Nesse contexto de crítica, os estilos de ser homossexual masculino podem ser postos em causa.

Veja-se, por exemplo, a imitação feita por Leo $^{5}$ da Oiá pagodeira ${ }^{6}$ Chega a "bichinha de candomblé no final de carreira [...]". Um "coroa que usa calça de tergal branca, presa acima do umbigo por um cinto preto, camisa ensacada, os bagos ficam repartidos no meio pela marca da braguilha, como que formando uma xexequinha". ${ }^{7}$ A descrição é verbal, mas, simultaneamente, Leo vai compondo, nele mesmo, a personagem, rearrumando seu vestuário, de forma a melhor caracterizá-la.

No meio da (suposta) festa, a kaku ("bicha" idosa) entra acompanhada de mais algumas "bichinhas". Leo encena. De alguma porta, entra rebolando. No ponto onde, imaginariamente, estão os atabaques, ele coloca a mão no chão e na cabeça (cumprimento habitual a visitas ilustres, quando chegam a um terreiro e a festa já se iniciou) - tudo é realizado de forma espalhafatosa. A assistência de Leo, já antevendo o que vai acontecer, transforma-se em coro e começa a cantar para Oiá. Segue o "barravento" (indicação de que o "santo"

5 Todos os nomes mencionados são fictícios, para guardar o anonimato dos interlocutores. Leo tem 21 anos e é iâ̂, negro, homossexual em parceria fixa, de classe popular.

6 Divindade feminina associada às tempestades.

7 "Bicha": homem com prática homossexual, efeminado; "coroa": homem na faixa dos 50 anos; "bagos": testículos; "xexeca": vulva. 
quer incorporar), a kaku sai, apoiando-se nas várias pessoas presentes, dando, de vez em quando, uma paradinha, abrindo os olhos para ver se as pessoas estão prestando atenção - sinal de que a pessoa está dando ekê (simulando o transe). Iansã incorpora-se, sob as gargalhadas da plateia. Seguem várias cantigas que acenam para o sexual e fazem parte de seus orôs (mistérios). Contudo, Leo leva ao exagero o que é apenas acenado, quando Oiá realmente está presente. Na cantiga Zambelê Zambelê, por exemplo, em que, como mandam os scripts sagrados, Oiá deve procurar os "santos homens" para cortejar, a pagodeira simula levantar as saias e se "atraca" com algum dos presentes, como numa verdadeira interação sexual.

Os alvos de Leo são as próprias "bichas", no candomblé denominadas adés - categoria na qual ele também se inclui -, sobretudo as kakus, que, "na falta de outros atrativos, usam do santo para chamar atenção". O que poderia ser visto como blasfêmia contra uma divindade, no candomblé, é um recorrente jogo jocoso. Leo brinca com uma situação que muitos de seus espectadores vivem ou viverão - tornar-se "bicha velha" -, ao mesmo tempo em que coloca em discussão o transe (possibilidade de $e k \hat{e}$ ), o próprio padrão erótico de Oiá e seus filhos e dos adés em geral.

Também o linguajar religioso é usado para falar dos corpos e prazeres. Por exemplo, o termo oro, utilizado para referir os momentos mais sagrados e misteriosos da religião, é utilizado para designar segredos profanos e fofocas e para denominar o ato sexual. "Dar o bife pra Exu" é o mesmo que ter sexo. Há ainda termos propriamente sexuais, como edi (ânus), amapô (vagina) e ocâni (pênis). $\mathrm{Na}$ verdade, as expressões sexuais se multiplicam ad infinitum. Tudo pode assumir, na brincadeira, duplo sentido e ganhar ares de eroticidade (Teixeira 1987).

Nesse contexto, a interpretação de Bakhtin (1996), referente à cultura popular na Idade Média e no Renascimento, caberia em muitos sentidos para descrever o funcionamento do sistema erótico apresentado nos terreiros, seja em seus aspectos de carnavalização do mundo, na conversão do sagrado em objetos de burla e blasfêmia e, sobretudo, na ênfase na vida material e corporal (imagens do corpo, da bebida, da comida, da satisfação de necessidades naturais e, principalmente, da vida sexual) que se configura no que o autor conceitua como realismo grotesco. Conforme Bakhtin (1996), por meio desse regime de imagens, ditos e atos, o social (cultura popular) ritualizaria, na degradação e materialização, a fertilidade, o crescimento e a superabundância, e se renovaria, brincando, criticando e rindo de o que é instituído.

Contudo, o que tenho chamado de cultura sexual se desdobra em vários registros. Ainda que eu tenha enfatizado até aqui aspectos do que é conceituado como sexualidade ou verdade e erótico ou prazer, outra lógica entra neste 
quadro, dialogando com essas e informando como os sujeitos podem ou não se conduzir no mundo sexual. Nesse âmbito, sublinho, em meio a um tom jocoso e aparentemente de muita liberalidade em relação aos prazeres do baixo corporal, as políticas dos gêneros se realizam, marcando, hierarquizando, dando privilégios a alguns e até punindo outros. Para abordá-las, recorrerei à análise da curta trajetória de um ogã , Weliton, no terreiro emergente Ilê Axé Ofá-megi.

\section{Caminhos e descaminhos para um jovem ciborgue}

Weliton, na época da pesquisa, era um jovem de 18 anos, filho de Oxalá, orixá da criação. Confirmou-se ogã ainda quando era criança e, com a morte de seu último pai de santo, frequentava o Ilê Axé Ofá-megi, no intento de lá fazer a nova moradia de seu orixá e oferecer seus préstimos de tocador de atabaque. Nada de mais teria o desenrolar dessa história, se o gênero não tivesse a função de operador que determina os lugares sociais das pessoas. Assim, logo o cargo do jovem foi colocado em causa, à medida que as interações se estreitaram e a performance cotidiana do rapaz começou a ser interpretada a partir dos referenciais do grupo:

"Ele chega lá como homem, e todo mundo vê que aquele Motorola é Samsung, que aquela Coca-Cola é Fanta. ${ }^{9}$ [...] Ele é muito afeminado [...] É o comportamento, realmente, a linguagem dele [...] toda feminina, não feminina, é toda de veado mesmo! Aquela coisa: 'Tá, meu amor, você 'tá boa?' [...] Naquele dia que foi festa de Omolu, que ele chegou com um idé [pulseira] dourado. Aquilo foi tudo. Quando ele falou que tem medo, que ele odeia bicho, principalmente aranha [...]" [Flávia]. ${ }^{10}$

"É o jeito dele, aparência [...] unhas grandes, lentes de contato [coloridas], muitas intimidades com mulheres que ele nunca viu. Já vem logo com aquela intimidade. Então, a gente já vê logo que a pessoa..." [Cristiane]. ${ }^{11}$

Jocosamente, todos no terreiro passaram a apelidá-lo de Ogã Arranca Toco. ${ }^{12} \mathrm{O}$ pseudônimo, ao mesmo tempo em que é referência a um caboclo da umbanda, tem forte conotação sexual, na qual o "toco" assume o aspecto fálico, que, quando articulado ao termo "arranca", imputa sentidos de passividade sexual a quem é atribuído.

Alguns eventos do contexto estudado acenam para um paradoxo na apreensão das coisas (homo)sexuais. O próprio terreiro Ofá-megi é dirigido por um pai de santo assumidamente homossexual, ainda que não efeminado. No Ilê

9 A contraposição de marcas denota ambiguidade.

10 Tem 36 anos e é iâ̂, branca, heterossexual, separada, de classe popular.

11 Tem 34 anos e é iaô, negra, heterossexual, casada, de classe popular.

12 Embora o apelido seja fictício, obedeço à lógica da atribuição. 
Axé, outros homens com práticas homossexuais, como Leo (aquele do ekê da Oiá pagodeira), assumem, sem problemas, diferentes posições de gênero e da hierarquia do terreiro. Então, que mal haveria em um jovem adepto do candomblé apresentar características que são concebidas como sendo da ordem do feminino?

Para entender o preconceito dirigido ao jovem ogã é preciso aprofundar a discussão por dois caminhos: investigar o sistema de gênero do candomblé, afinal, os atributos agenciados por ele são acionados para destituir sua imagem; e a divisão do trabalho religioso, em especial, as atribuições concernentes ao cargo de ogã (na brincadeira, Weliton vinha sendo confrontado com essas atribuições). Iniciarei pelo gênero.

\section{Metá: a lógica da hibridização}

No candomblé, cada indivíduo é relacionado a um deus, que, no caso dos rodantes, pelo processo de iniciação, passa a ter legitimidade para possuir o "filho". Para rodantes ou não, a identificação do "orixá de cabeça" está embasada na crença de que o processo de criação individual se faz a partir de elementos da natureza. É a prevalência desses elementos, relacionados aos deuses, que torna a pessoa "filha" de dado orixá. Cabe ao pai ou mãe de santo, olhando o modo de ser da pessoa, consultando o oráculo e tendo em vista as características dos orixás, identificar o "santo de cabeça". Por outro lado, o processo de iniciação tem caráter adscritivo, oferece à pessoa um modelo identificatório (Augras 1983), o qual se inscreve numa singular matriz de gênero (Segato 1995). Essa matriz é constituída por três categorias: iabá, aboró e metá-metá (ou simplesmente metá). Cada uma delas reúne um conjunto de orixás, que se organizam como uma variedade de tipos ideais ou famílias, no sentido taxonômico do termo, de deuses. ${ }^{13}$ Ainda que os aborós tenham pênis e as iabás, vagina, homens e mulheres humanos podem ser "filhos" de, indistintamente, orixás aborós, iabás ou metás. ${ }^{14}$ Para a identificação do orixá, o que está em jogo é reiteração performática (Butler 2003) de atributos categorizados, ainda que difusamente, como no âmbito das categorias de gênero (iabá, aboró, metá) e das famílias-orixás.

Conforme Segato (1995), que investigou o xangô ${ }^{15}$ pernambucano, em que não ocorre a categoria metá, o núcleo duro da iabanidade é a dependência, em oposição à autonomia, núcleo duro da aboronidade. No candomblé, essa matriz categorial é incrementada pela ideia de qualidade, na qual a família-orixá (por

13 Iabá: Oxum, Iemanjá, Iansã, Ewá, Obá, Nanã; Aboró: Oxalá, Xangô, Oxóssi, Ogun; Metá: Oxumaré, Ossaim e Logun Edé.

14 No que se refere aos metás, Logun Edé e Ossaim são descritos como do sexo masculino. Já Oxumaré, em algumas versões míticas, aparece mudando de sexo de seis em seis meses.

15 Modo como é denominada a religião afro-brasileira africanista autóctone do estado de Pernambuco, no Nordeste do Brasil. 
exemplo, Oxum) agruparia várias espécies (também no sentido taxonômico) de seres míticos. Por exemplo, Ye yê Karê, Ijimum, Opará, Ipondá, que se assemelham em alguns atributos. Cada qualidade remete às relações míticas que uma divindade estabelece com outra, o que faz com que ela apresente, em si, características marcadoras de outros deuses. Por exemplo, Oxum, considerada a mais feminina das iabás, doce, meiga e sentimental, tem, na qualidade de Ye yê Karê, esposa de Ogum, o orixá da guerra, uma Oxum que empunha a espada e enfrenta luta.

Desse modo, o uso do termo qualidade para designar as várias entidades que participam de uma família-orixá abre passagem para as hibridações. Essa lógica, que permite que orixás e humanos se espelhem com mais facilidade, é potencializada na terceira categoria de gênero dos deuses, metá, e é expressa com dramaticidade nos mitos do orixá Logun Edé.

Filho incestuoso de Oxóssi e Oxum, Logun aparece nos mitos como um ser híbrido e em constante metamorfose. Ele passa de gente a peixe, a cavalo-marinho, o híbrido aquático cujo macho guarda a prole no ventre. Ser inconformado com os limites impostos pela biologia e pela sociedade, embora tenha pênis, cisma em se metamorfosear de iabá, para frequentar lugares aonde só elas podem ir, mas ele não lida muito bem com as tarefas domésticas, próprias das iabás, ou o trabalho da caça, atribuição dos aborós (Rios 1997).

Por analogia, talvez se tenha em Logun a prefiguração do ciborgue, centro da blasfêmia de Haraway (1994), em seu esforço político-teórico para criticar e desmantelar a ideia clássica de identidade e pureza, que legitima os processos de desigualdade no Ocidente. Com certeza, a autora não se referia a Logun e aos "santos metás", quando, usando a imagem do ciborgue, buscou refletir sobre o lugar do híbrido e das categorias em oposição na sociedade ocidental. Ainda assim, e brincando com as palavras da autora, posso dizer que esse orixá não tem "medo de seu parentesco com animais e máquinas, nem de suas identidades permanentemente parciais e pontos de vistas contraditórios" (Haraway 1994: 250). Logun e, amplamente, a lógica da metanidade, que guia a matriz de gênero do candomblé, demonstram que "as ideologias da reprodução sexual não podem mais considerar as noções de sexo e papel sexual como aspectos orgânicos em objetos naturais" (Haraway 1994: 260).

Todavia, em meio à "desordenada polifonia emergente da descolonização" (Haraway 1994: 252) da sexualidade e do gênero, e complementando aspectos do cenário cultural no qual os metás entabulam suas interações, surgem alguns mitos que poderiam ser interpretados como desfavoráveis à metanidade. Logun é constantemente perseguido pelos guardiões das normas, como Iemanjá, Nanã e seu pai Oxóssi (Rios 1997). Vale lembrar que, em certo nível, os mitos estão enraizados na realidade sociocultural abrangente, na qual imperam formações discursivas contrárias aos trânsitos entre sexo, 
orientação sexual e gênero. As passagens, então, parecem funcionar como "sinal de alerta", ao informar que os metás, por contrariarem a ordenação concebida como natural - homens são masculinos e mulheres são femininas -, são discriminados e perseguidos.

Em outras palavras, os mitos sinalizam que nem todo homem tem o direito de se apresentar por qualquer dos roteiros de gênero-família-espécie de orixá disponíveis nessa cultura sexual. Como já acenei, alguns cargos sacerdotais exigem determinados posicionamentos, que são, como tudo, generizados. Apresentarei, então, as normas de gênero do trabalho religioso, que Weliton se dizia pronto a realizar.

\section{OGÃ}

Conduzi uma entrevista coletiva com quatro iaôs do Ilê Ofá-megi, e a figura de Weliton ganhou proeminência, atualizando o desconforto da comunidade com seu modo de ser. Para ajudar a entender o que se passava, resolvi mencionar a sexualidade de outros ogãs conhecidos. Questiono se não poderia haver ogãs homossexuais, e Júlio ${ }^{16}$ se adianta: "O ogã é o símbolo [do] homem, né? Eu acho que tem que ser homem". Flávia completa: "Só que não existe ogã veado, homossexual. Ogã homossexual não pode!" No momento em que ela fala da impossibilidade, recordo-me de um casal conhecido dos presentes, no qual um dos parceiros era ogã de uma casa prestigiada, e o menciono para o grupo. Imediatamente Flávia objeta: "Quem comia quem?"17 Eu respondo: "Não havia isso, os dois se comiam..." Flávia, descontente, encerra a conversa: "Tudo bem, eu sempre ouvi meu pai [de santo] falar que não pode. Pelo menos eu acho que é o certo".

No candomblé, o termo "homem", usado por Júlio, condensa vários sentidos relacionados ao entendimento da vida sexual: "ter ocâni", "comer" (ser ativo na interação sexual), apresentar de forma prevalente características dos orixás aborós, explicitamente se apresentar como desejando mulheres. Essa configuração é nomeada okó (marido). Se, por acaso, nas fofocas, práticas homossexuais vierem a público, logo motivos extra(-desejos)-sexuais (por dinheiro, excesso de álcool, etc.) ou, como fez Flávia, a posição de penetrador, são utilizados para restituir o lugar de macho àquele que "foi para cama" com outro homem.

Por outro lado, o termo "homossexual", utilizado por minha interlocutora como anátema em relação aos ogãs, afasta-se do significado para o qual foi forjado no seio das ciências médicas, em que se refere a pessoas que interagem sexualmente com pessoas do mesmo sexo, e ganha o sentido de passividade

16 Tem 21 anos e é iâ̂, negro, homossexual em parceria fixa, de classe popular.

17 Quem penetrava quem? 
sexual, numa relação entre dois homens, que é reiterada no cotidiano por performances efeminadas de gênero. Como mencionado, essa configuração de sexo-gênero ganha, nos terreiros, a nomeação de adé.

Quando se trata dos ogãs, os signos da homossexualidade, passividade e feminilidade assumem, de modo mais explícito, valor negativo, parecendo degenerar a imagem daqueles, destituindo-os das qualidades necessárias para o exercício de suas funções na divisão do trabalho religioso. Lembro que, nos tempos da perseguição aberta às religiões afro-brasileiras, muitos ogãs eram escolhidos entre personagens ilustres da sociedade (artistas, escritores, políticos, militares, antropólogos, etc.), e realizavam a mediação dos terreiros com as instituições do mundo exterior. Eles intercediam na polícia, nos serviços de saúde mental, na academia, dentre outros, garantindo o funcionamento dos terreiros (Rodrigues 1935; Santos 2002).

Hoje, quando a polícia não mais realiza "quebra-quebras", os ogãs que não se ocupam dos atabaques nos dias de festa recebem os convidados e guardam a ordem da comunidade, enquanto o pai ou mãe de santo realiza o trabalho religioso. Nesse âmbito, a questão que se põe a meus entrevistados é: como um veado poderia assumir tais funções? Que respeito poderia obter das pessoas de lá e de cá?

Por tudo isso, um ogã além de não poder incorporar um santo, pois precisa se manter em vigília para exercer suas funções, deve se portar de modo o mais formal possível, como prescrito para um homem quanto à postura, com contenção dos "gestos largos", com atenção para o local certo onde "pousar a mão". Deve ter atenção também às formas de rir e de olhar. Lembro de alguém falando até das roupas que um ogã deve vestir: "Calça de linho e camisa de botão, sapato engraxado [...]".

Weliton não observou a regra de apresentar-se publicamente como okó, como cabe a um ogã e pagou os ônus por seus rompantes de adeicidade. Após alguns meses de frequência ininterrupta da casa, o pai de santo resolveu tirar a prova dos nove: consultou os búzios para confirmar o santo e o cargo do rapaz. O terreiro inteiro mobilizou-se e, respeitando o pensamento do grupo, os búzios não mentiram: naquele Ilê Axé ele jamais seria ogã. O pai de santo foi categórico: Weliton não era de Oxalá, mas de Xangô, e rodante. O jovem caiu em lágrimas.

Acostumado a "correr gira", ${ }^{18}$ Weliton teria de abrir mão dos privilégios próprios dos ogãs - ser reconhecido e saudado como um "mais velho" da religião, e todas as prerrogativas que isso implica. Ele voltaria a ser abiã (noviço), e posteriormente, quando iniciado, seria iâo, serviria os "mais velhos", cuidaria dos afazeres mais básicos necessários à manutenção da casa (lavar louça, 
varrer, cuidar dos banheiros, etc.). Sentaria no chão, pois só os "mais velhos" têm direito à cadeira, manter-se-ia de cabeça baixa. Assim, iniciaria o percurso de galgar a hierarquia - o que nunca cumpriu antes, pois ogãs e equedes, quando iniciados, tornam-se logo ebômis. No mínimo, eram sete anos de obrigações cumpridas para voltar a sentar em cadeira e olhar os "mais velhos" cara a cara.

Nosso protagonista não se fez rogado e iniciou um namoro com uma frequentadora do grupo, como querendo expressar a virilidade sexual necessária ao ogã , mas isso não foi suficiente para ser restituído ao lugar almejado. Mais importante do que o que ele "fazia na cama" era o que expressava no cotidiano da casa de santo, e, em especial, nos dias de festa, quando o terreiro se abre para o mundo. Ele continuava usando suas lentes de contato coloridas, suas pulseiras douradas, mantinha seus maneirismos. Por fim, talvez porque tenha se conscientizado de que não receberia seu "cargo" de volta, Arranca Toco deixou aquele terreiro, em busca de outro menos rígido quanto às prescrições em termos de gênero para um ogã.

\section{"Homem mesmo", sob suspeita}

$\mathrm{Na}$ busca por adensar elementos etnográficos e históricos para a compreensão da participação de homens com práticas homossexuais efeminados nos terreiros afro-brasileiros, Matory (1988) chama atenção para o simbolismo da possessão entre os Iorubás na África negra. Os religiosos africanos associam as pessoas capazes de vivenciar a possessão à submissão na relação com um ser mais poderoso, expressa num arranjo simbólico em que os possuídos são associados a vasos, cavalos ou esposas. Em contraposição, os orixás, femininos ou masculinos, ocupariam o lugar de conteúdo, cavaleiro, marido, o pólo da autoridade e do poder.

Nesse contexto, diz o autor, embora "a taxonomia iorubá não reconheça uma categoria de homens regularmente montados por outros homens" (Matory 1988: 229), a pragmática do gênero admite que o homem seja "esposa" do orixá, e adote, ritualmente, roupas e penteados femininos. Para Matory (1988), no Brasil, esse sistema de entendimento da relação entre deuses e humanos sexualiza-se quando se articula com o simbolismo do gênero da sociedade mais ampla, na qual as práticas homossexuais masculinas são situadas culturalmente a partir da polaridade entre homens ativos, masculinos, homens mesmo, penetradores e, no outro extremo, passivos, femininos, "bichas", penetrados. A superposição simbólica que se cria abriria a possibilidade do engajamento dos homens efeminados como rodantes.

Trabalhando no contexto etnográfico do candomblé do Rio de Janeiro, Patrícia Birman $(1995,1997)$ vai além no estabelecimento de relações entre gênero e transe e propõe a possessão como capaz de criar categorias de gênero no candomblé, um operador generizante: 
"Com efeito, é possível associar dois elementos já destacados: uma divisão de gênero que exclui da condição plena de homens aqueles que viram no santo; e a atribuição de uma masculinidade plena unicamente aos homens que no candomblé não praticam a possessão, os ogãs" (Birman 1995: 87).

Birman (1995) sugere uma gradação de gênero superposta à hierarquia do terreiro, na qual ogãs e equedes, por não "virarem no santo", estariam relacionados ao pólo masculino, assim como mães, pais, filhas e filhos de santo e adés, ${ }^{19}$ afetados pela possessão, atualizariam feminilidades:

"[...] a condição de filho de santo corresponde a um gênero na medida em que este adquire, por intermédio do processo de iniciação, certas marcas irreversíveis e que dizem respeito à sua definição em termos de estatuto sexual. Essas marcas na verdade reduzem-se a uma, fundamental: trata-se da já mencionada perda de virilidade provocada pela possessão" (Birman 1995: 98).

A argumentação da autora sugere superposição entre o que ela denomina estatuto de gênero e identidade sexual. Assim, no arranjo simbólico proposto, a iniciação, ao capacitar a pessoa para a possessão, cria nos homens uma ambiguidade sexual (homossexualidade) que também os feminiza:

"[...] de uma definição primeira nenhum filho de santo escapa - ainda que de uma forma não consciente essa condição revele um estatuto de gênero específico, dado pela relação com a possessão. A ambiguidade em termos da identidade sexual vincula-se ao que há de específico nessa condição, e é dela que devemos nos ocupar para melhor entender esse fenômeno" (Birman, 1995: 99).

Não quero dizer que, do ponto de vista nativo, a leitura sobre a homossexualidade por meio da performance de gênero inexista. De fato, no caso do candomblé, do mesmo modo que na sociedade abrangente, efetivamente, muitas vezes, ela ocorre. Não obstante, se a possessão tem, de fato, implicações para a realização do trabalho religioso, meus dados empíricos mostram que ela é insuficiente para configurar tanto o gênero como a orientação sexual dos adeptos.

No terreiro Ofá-megi, na época da pesquisa, o número de mulheres superava, em dobro, o de homens. O número de homens rodantes, heterossexuais (casados ou não) quase se igualava ao número de homens declaradamente homossexuais - cerca de 18 homens no total. Não havia cogitação sobre a

19 Embora a autora proponha adé como categoria sacerdotal, stricto sensu ela não se configura como tal, mas como categoria de gênero-sexualidade. 
masculinidade dos rodantes heterossexuais. Havia uma filha de santo assumidamente casada com mulher, e bastante feminina.

No terreiro, havia quatro equedes, nenhuma delas era masculinizada nem pesava sobre elas a suspeita de homossexualidade. Uma era uma criança de seis anos, duas outras eram mulheres casadas cujos maridos e filhos faziam parte da comunidade, e uma quarta era viúva, iniciada na casa de primeira geração da linhagem de santo do Ofá-megi, cuja filha e neta se iniciaram no Ilê Axé emergente. Inclusive, uma das imagens que o pai de santo gostava de enfatizar para marcar sua casa de santo era o fato de ela ser frequentada por famílias, nas quais genitores e prole se iniciavam em seu terreiro.

Além dos rumores sobre Weliton, no Ilê Axé Ofá-megi havia um disse me disse entre os homens com práticas homossexuais sobre, pelo menos, dois outros ogãs. Ambos eram masculinizados do ponto de vista do sistema de gênero do grupo, no entanto, diziam sobre Pai Lucivaldo e Pai Francelino que, embora se dissessem heterossexuais, também tinham sexo com homens. Mais importante é enfatizar que, nesses casos, ninguém nunca cogitou sobre o cargo. Suas posturas combinavam, aos olhos da comunidade, com o prescrito para os ogãs - "montassem" ou "fossem montados" por homens na cena privada.

Se masculinidade e feminilidade, quando agenciadas pelas pessoas, provocam leituras sobre orientação sexual, os homens efeminados, em geral, não buscam a realização sexual entre si. Os scripts de sexualidade-gênero exigem que eles busquem os "homens mesmo", os okós, como parceiros sexuais (Fry 1982; Parker 1991). Sobre isso, diz Saulo: ${ }^{20}$ "Os adés querem transar com, entre aspas, os okós, os homens, os machos, né? Que têm atração, mas escondem esse fato". E reitera: "Tem muito ogã que faz a linha, ${ }^{21}$ tá? Não vem que não tem não, tá?” Para exemplificar, Saulo conta a seguinte situação:

"Estive semana passada num 'toque' lá em Belfort Roxo. Tinha um ogã que desde que pisei no terreiro ele não tirava os olhos de mim. [...] Pô, o cara tinha hora que me incomodava. [...] E o ogã é casado [com mulher], ele é casado! [...] Eu posso te assegurar que os ogãs não são tão okós assim, não. Tem as suas diversificações!”

O que quero sublinhar é que, ainda que o foco de Birman (1995) tenha sido as representações de gênero, a autora parece ter dado pouca importância ao relato de seus informantes adés e ogãs sobre suas práticas e parcerias sexuais, pois apreendeu e discutiu apenas um dos estatutos de gênero que a identidade (homo)sexual pode assumir. Talvez isso tenha sido efeito da própria posição de sexo, sexualidade e gênero da pesquisadora, que matiza as possibilidades 
dos relatos dos interlocutores. ${ }^{22}$ Além disso, por interesse de pesquisa, eu estava atento ao modo como parcerias e práticas sexuais se expressavam publicamente, e pedia para que as pessoas me falassem delas. Por outro lado, talvez o próprio fenômeno da AIDS tenha se interposto, na medida em que, na época de meu trabalho de campo, estava amplamente consolidado o discurso médico das categorias e práticas de risco, que situa o potencial de perigo das transações sexuais, em especial para homens homossexuais e bissexuais. Tudo isso pode ter contribuído para que as dúvidas sobre a orientação sexual dos "homens mesmo" aparecessem no campo discursivo, na ocasião de conversas e entrevistas.

De certo modo, um conjunto de relatos que coloca em cheque a relação proposta por Birman (1995) - a possessão como capaz de criar orientação sexual e, portanto, um determinado estatuto de gênero -, à medida que as representações também situam os ogãs e outros "homens mesmo" como possíveis parceiros sexuais dos adés. Nesse arranjo simbólico, ficam todos, okós e adés, sob o peso da ambiguidade que certo dito popular coloca para as interações sexuais entre homens: entre quatro paredes vale tudo (Parker 1991).

Assim, quando se sai do âmbito do mundo dos modelos ideais, onde os ogãs são, por exemplo, considerados "homens mesmo", aproximando-se do mundo real, vê-se que, no terreiro, são eles que estão sob maior suspeita. O fato é que a assunção performática da homossexualidade pelos adés tira-os da ordem da ambiguidade. Os olhares e as fofocas se voltam, sobretudo, para os não "adeemente" identificados, sejam rodantes ou não. As dúvidas se localizam, sim, nos homens okós. Afinal, é da ordem do erótico que a possibilidade de converter sexualmente alguém torne a empreitada mais perigosa e com maior possibilidade de se obter prazeres, não só físicos, mas também discursivos. Ressalto que se trata de suspeita sobre orientações e posições sexuais, mas não sobre estatuto de gênero. Por isso, esses homens em nada são abalados em relação a seus "cargos".

Voltando à compreensão do caso de Ogã Arranca Toco, ele, que jamais entrou em transe, não se feminizou por conta disso. Weliton era percebido como efeminado, desde que chegou ao terreiro. A (possibilidade de) possessão, ao invés de configuradora de sua identidade de gênero, foi importante elemento disciplinador. Depois de muitos esforços para ensinar-lhe como um ogã deve se portar, foi acionado o transe, como a derradeira estratégia para, mudando a

22 Nas conversas que presenciei nos terreiros, adés e okós mantinham, frente às mulheres, a associação okós-masculinidade-heterossexualidade e adés-feminilidade-homossexualidade - assim procedeu Júlio, reiterando que "ogã é símbolo [do] homem", completado por Flávia: "Não pode ser homossexual". Mas, o mesmo Júlio sabe que não é bem assim, pois, noutra ocasião, comentara comigo sobre as investidas de Ogã Lucivaldo sobre ele. Quando não era mais possível dissimular a homossexualidade de um okó (rodante ou não), buscava-se manter a partição masculino-penetrador versus feminino-penetrado entre os envolvidos. Assim fez Flávia, quando eu explicitei que o modelo penetrador-penetrado não valia para o casal sobre o qual conversávamos. Pareceu-me que eu estava revelando um segredo interditado às mulheres, que, explicitado, desarrumou o esquema de inteligibilidade utilizado por Flávia. 
inscrição, mantê-lo no terreiro. Dizer que ele era rodante e precisava se iniciar como tal, caso Weliton aceitasse, iria deslocá-lo em direção a uma posição hierárquica que pudesse ser compatível com sua performance de gênero.

Em minha compreensão, embora a possessão tenha papel chave na configuração de gênero, ela é insuficiente como operador de gênero, pois precisa estar articulada às atribuições religiosas a ser desempenhadas pelos homens quando ingressam na hierarquia religiosa. A possibilidade de possessão não causa representações de feminilidade, são as performances de gênero das pessoas que, ao ser lidas, indicam, dentre outras coisas, possibilidades de localização no terreiro.

\section{Homens e gênero: sobre trabalho}

Nos terreiros de candomblé queto fluminenses, se os jovens rodantes podem, ao chegar à comunidade, apresentar-se femininos "um pouco além da conta", quando se tornam ebômis e são chamados de pais pelos "mais novos", precisam fazer valer o status alcançado. À medida que galgam a hierarquia religiosa e incorporam posições mais centrais na mediação terreiro-mundo, exige-se cada vez mais que modifiquem suas performances, diminuindo as "pintas" 23 e, sobretudo, as "fechações", ${ }^{24}$ em especial, nos momentos em que as comunidades se abrem ao público nas festas, de forma a "melhor" representar o terreiro como uma casa de tradição. Pode-se mesmo dizer que galgar as idades da hierarquia sacerdotal para rodantes também é um aprendizado de gênero.

A literatura de gênero e feminista aponta o lugar estruturante da divisão do trabalho ${ }^{25}$ entre os sexos (ao lado do tabu do incesto e da homossexualidade) na criação da assimetria e da complementaridade necessárias para que a reprodução (biológica e) social se cumpra (cf., especialmente, Rubin 1993). De outro modo, no alinhamento que o sistema de sexo-gênero busca incessantemente empreender, as posições de trabalho entram, junto com a gestualidade, os adereços corporais e as práticas sexuais, como importantes elementos na reiteração da naturalização da assimetria e complementariedade entre homens e mulheres.

Para iluminar minha argumentação, estabeleço analogias entre o que observei nos terreiros e em alguns outros espaços socioculturais e as regulações de gênero concernentes à divisão do trabalho. Assim, mudando o contexto, também observei que as "bichas" não candomblesistas, à medida que ficam

23 Demonstração de gostos sexuais por via de performances femininas desempenhadas por homens.

24 Conduta pouco usual, utilizada para chamar atenção. Quando aplicado aos adés revela o comportamento percebido como histriônico-caricato que eles realizam pelo uso de coisas femininas. Embora no contexto em estudo "fechação" e "pinta" se refiram a performances femininas realizadas por homens, a primeira tende a ser usada para referência a um ato proposital, enquanto a segunda usualmente se refere a uma conduta não intencional.

25 Trabalho aqui é concebido no sentido lato: a divisão de tarefas necessárias para a reprodução de um grupo, comunidade ou sociedade. 
mais velhas e precisam se engajar no mundo do trabalho, fora dos espaços gay ou serviços de estética, "se endurecem", diminuindo, tanto quanto possam, as pintas em suas performances públicas. Lembra-se que, na sociedade brasileira, um homem feminino é tudo o que um "macho de verdade" não deve ser ou se tornar. A feminilidade degenera seus corpos e almas (Lancaster 1999), desabilita-os, dentre outras coisas, a assumir muitos dos postos de trabalho socialmente disponíveis para os homens (Rios 2004; Rodrigues e Nardi 2008).

Também não posso deixar de mencionar o caso guaiaqui, tornado clássico por Pierre Clastres (1978). Refiro-me ao homem que não sabia lidar bem com as tarefas masculinas: não sabia usar o arco e, como as mulheres, cuidava da coleta. Por tudo isso, era rechaçado pela comunidade, mas não era descrito ou se descrevia como se sentindo atraído por homens, tampouco usava adereços e gestualidade que o remetessem ao feminino. Outro guaiaqui, entretanto, também não sabia lidar com as tarefas masculinas, vestia-se como mulher e fazia sexo com homens. Ele era bem visto pela comunidade (que parecia não se preocupar tanto com o sexo biológico, no momento de classificar e valorar as pessoas), uma vez que sua orientação erótica combinava com a performance de gênero e as regras da divisão do trabalho.

Dos guaiaquis à sociedade ocidental, o primeiro ponto a ser destacado é a ênfase na biologia como lócus de onde as classificações devem sair e para onde devem convergir (Rubin 1993; Butler 2003). Além disso, e ainda que pesem as mudanças sociais relacionadas aos reposicionamentos da mulher na sociedade ocidental contemporânea, pode-se afirmar que, enquanto o trabalho doméstico, realizado pelas mulheres, tem recorrentemente ganhado o sentido de não trabalho, o que faz com que as subjetividades das mulheres se organizem a partir da ideia de cuidado com a casa, o cônjuge e a prole, o trabalho na esfera pública tem proeminência simbólica para organizar as identidades dos homens (Duarte 1986).

Os fragmentos etnográficos acima mencionados, que analisam espaços sociais em que homens circulam e são avaliados em suas masculinidades, apontam para uma importante inter-relação entre trabalho, gestualidade e adereços e fontes privilegiadas de prazeres corporais; para a economia política do sexo-gênero; para a organização das configurações de estilos de estar no mundo que os homens precisam apresentar; para sinalizar competência rumo à colocação laboral que querem ou precisam assumir no grupo, comunidade ou sociedade em que se inserem.

Voltando aos terreiros que investiguei, mostrei como o processo estigmatizante contra homens femininos é atenuado pelo desafivelamento entre sexualidade e reprodução biológica, que, de certo modo, quebra o tabu da homossexualidade. Tal desafivelamento parece abrir caminho para a lógica da metanidade, tornando legítimo, para os adeptos homens, uma amplitude maior de agenciamentos contra-hegemônicos de gestualidades e adereços 
classificados como femininos. Não obstante, é preciso notar que o processo de desessencialização parece ter seus limites, reside no âmbito da divisão do trabalho religioso especializado, que é repartido por sexo. Como mostrei no início do texto, a divisão do trabalho religioso reafirma uma bipolaridade humana, causada pelo "tabu do trabalho", que pede a complementaridade entre os sexos para que ocorra a reprodução social dos terreiros. ${ }^{26}$

Por tudo isso, sugiro que não é propriamente a possessão o operador que mobiliza as performances de gênero dos homens de candomblé. Em minha interpretação, no candomblé queto, é o trabalho que insta alinhamentos entre as dimensões sexo, gênero e prazer sexual da pessoa, de modo que os indicadores sociais relativos a essas dimensões se organizem, para sinalizar o lugar que deve assumir para o exercício religioso.

Nos candomblés que estudei, o processo estigmatizante tende a se acentuar sempre que alguém realiza mediação com a sociedade abrangente, na qual as homossexualidades, em especial as ditas pelo feminino, ou seja, as que são sinalizadas por atributos de feminilidade, como já mostrei, são pouco toleradas. Se isso é verdade para todos os ebômis, no caso dos ogãs, as exigências parecem se acentuar, dado ao caráter protetivo que lhes foi imputado pelas primeiras mães de santo baianas.

Posso até dizer que é a esse alinhamento entre sexo e gênero (que sinaliza prazeres nas posições sexuais), necessário para o exercício do trabalho religioso, que se referem os elementos analisados:

- a encenação cômica de Leo sobre os adés: homens mais velhos, femininos, não são verdadeiramente competentes para assumir o compromisso sacerdotal de oferecer seus corpos para que, por meio do transe, as divindades possam chegar no aiê;

- as narrativas míticas sobre os metás: a variedade e a fluidez nos agenciamentos de gestos, adereços e prazeres fazem com que os híbridos (deuses e humanos) não realizem, com competência, tarefas masculinas ou femininas;

- os dramas pessoais, como o de Weliton: ogã é homem respeitável, não pode configurar feminilidade, que sinaliza passividade sexual, se quer ser respeitado nas tarefas de chamar o orixás com o toque dos atabaques, oferecer-lhes sacrifícios, receber as visitas e manter a ordem da casa em dias de festa.

26 É justamente no processo iniciático que a complementaridade dos sexos tem a melhor visibilidade: os homens sacrificam e tocam para chamar os deuses; as mulheres, no Ipadê, comunicam quem deve vir para a cerimônia, aplacam as iamis e, na culinária sagrada, transformam sacrifício e oferendas em axé especializado, de modo que a capacidade gerativa do encontro entre os sexos possa se realizar no fazer uma nova $i a \hat{o}$. 
CONSIDERAÇÕES FINAIS: FEMINILIDADE, CANDOMBLÉ DO "VEADEIRO" E O PARADOXO DOS PRAZERES

Finalizando, preciso sublinhar que nem todo candomblé apreende os homens femininos do modo acima descrito para o candomblé queto que estudei no Rio de Janeiro. Como meu espaço de escrita está chegando ao fim, deixarei para outra oportunidade uma comparação mais aprofundada entre esses e os que eles qualificam como "candomblés do veadeiro" (Rios 2002), modalidade que tive a chance de investigar com mais cuidado em Recife (Rios 1997). Muito assemelhado ao terreiro estudado por Fry (1982) em Belém, nesses, a feminilidade dos homens é notória. Por conta disso, vêm, desde Ruth Landes (1967), no mais das vezes, sendo preteridos pela academia, que, juntando-se às políticas identitárias do discurso nativo ou ajudando a constituí-las, coloca-os como pouco tradicionais ou mesmo degenerados.

Nos candomblés (ditos) do "veadeiro", a lógica da metanidade parece ir além na desorganização da economia política de sexo-gênero heteronormativa, alcançando o trabalho religioso e possibilitando, inclusive, a presença de ogãs-adés (Rios 1997). Não obstante, em geral, esses terreiros têm pouca expressão no cenário afro-brasileiro mais amplo, pois são profundamente estigmatizados pelos terreiros considerados tradicionais.

Voltando mais uma vez aos terreiros de candomblé queto, mas sem perder de vista a questão da feminilidade, também é importante sublinhar que, quando o assunto é possibilitar a interação sexual e afetiva entre os homens, algo do feminino precisa permanecer. Afinal, dentro e fora dos terreiros, gestos e adereços corporais sinalizam publicamente os gostos sexuais, em termos de objeto (homem ou mulher) e de objetivo (ativo ou passivo).

Sobre isso, lembro uma festa de candomblé na qual André, um jovem ogã , que eu sempre percebi como masculinizado, caiu de encantos por um iâ̂ biologicamente mais velho que ele, também masculinizado. Entre os flertes da paquera, fui percebendo o ogã paulatinamente se feminizando, talvez porque, no jogo da conquista, o iaô tenha se negado a configurar o feminino, na díade que marca os roteiros de parcerias nos terreiros. Ainda nesse mesmo caminho, situado pela matriz heterossexual, talvez tenha sido uma forma de sinalizarem, reciprocamente, seus gostos entre quatro paredes. Ressalto, contudo, durante um ano e pouco em que convivi mais proximamente com André, a performance efeminada restringiu-se ao dia de festa, fora dos olhares de sua casa de santo, onde esteve sempre na posição de "homem mesmo".

Convém salientar que essa possibilidade de performances situacionais de gênero, guiadas pelos interesses sexuais pessoais, não é exclusiva dos adeptos do candomblé, espalha-se mais amplamente nos diferentes espaços onde homens com práticas homossexuais pautam suas interações a partir do modelo bipolar. Nos jogos identitários, os lugares ocupados não se parecem tanto com 
entidades fechadas e exclusivas, mas, como diria Perlongher (1984), são como pontos de um contínuo.

Talvez aí resida o verdadeiro paradoxo oferecido pela cultura sexual dos terreiros de candomblé queto a seus partidários homens com práticas homossexuais: se apresentar a um só tempo masculino e feminino, de modo a ser respeitado pela comunidade, mas sem perder a capacidade de sinalizar no corpo quem se quer e o que se quer, em termos dos prazeres sexuais.

\section{BIBLIOGRAFIA}

AUGrAS, Monique, 1983, O Duplo e a Metamorfose: A Identidade Mítica em Comunidades Nagô. Petrópolis, Vozes.

BAKHTIN, Mikhail, 1996, A Cultura Popular na Idade Média e no Renascimento: O Contexto de François Rabelais. São Paulo-Brasília, Hucitec/Edunb.

BIRMAN, Patrícia, 1995, Fazendo Estilo, Criando Gênero. Rio de Janeiro, Relume Dumará.

—_, 1997, "Futilidades levadas a sério: o candomblé como uma linguagem religiosa do sexo e do exótico", em Hermano Viana (org.), Galeras Cariocas: Territórios de Conflitos e Encontros Culturais. Rio de Janeiro, UFRJ, 227-245.

BUTLER, Judith, 2003, Problemas de Gênero: Feminismo e Subversão da Identidade. Rio de Janeiro, Civilização Brasileira.

Clastres, Pierre, 1978, "O arco e o cesto", em Pierre Clastres, A Sociedade contra o Estado. São Paulo, Brasiliense, 1 19-143.

DUARTE, Luís Fernando Dias, 1986, Da Vida Nervosa nas Classes Trabalhadoras Urbanas. Rio de Janeiro, Zahar/CNPq.

FRY, Peter, 1982, Para Inglês Ver: Identidade e Política na Cultura Brasileira. Rio de Janeiro, Zahar.

—, 2010, "Presentation", Vibrant, l (7): 7-10.

HARAWAY, Donna, 1994, "Um manifesto para os cyborgs: ciência, tecnologia e feminismo socialista na década de 80", em Heloísa Buarque de Hollanda (org.), Tendências e Impasses: O Feminismo como Crítica da Cultura. Rio de Janeiro, Rocco, 243-288.

LANCASTER, Roger, 1999, “That we should all turn queer?': Homosexual stigma in the making of manhood and the breaking of a revolution in Nicaragua", em Richard Parker e Peter Aggleton (orgs.), Culture, Society and Sexuality: A Reader. Londres, UCL, 97-1 16.

LANDES, Ruth, 1967, A Cidade das Mulheres. Rio de Janeiro, Civilização Brasileira.

MATORY, J. Lorand, 1988, "Homens montados: homossexualidade e simbolismo da possessão nas religiões afro-brasileiras", em João José Reis (org.), Escravidão e Invenção da Liberdade. São Paulo, Editora Brasiliense, 215-231.

PARKER, Richard, 1991, Corpos, Prazeres e Paixões: A Cultura Sexual no Brasil Contemporâneo. São Paulo, Best Seller. 
PERLONGHER, Nestor, 1984, "Amor e comércio na prostituição viril", em Anais do IV Encontro da ABEP, vol. 1. Águas de Lindoia, ABEP, 124-134.

RIOS, Luís Felipe, 1997, Lôce lôce, Metá Rê-lê!! Homossexualidade e Transe(tividade) de Gênero no Candomblé de Nação. Recife, UFPE, dissertação de mestrado.

— 2002, "Em busca da tradicionalidade: geração, gênero e sexualidade no candomblé baiano-carioca", Boletim Sexualidade, Gênero e Sociedade, 17: 1-8.

—, 2004, O Feitiço de Exu: Um Estudo Comparativo sobre Parcerias e Práticas Homossexuais entre Homens Jovens Candomblesistas e/ou Integrantes da Comunidade Entendida do Rio de Janeiro. Programa de Pós-Graduação em Saúde Coletiva, Universidade do Estado do Rio de Janeiro, dissertação de doutorado.

RODRIGUES, Manoela Carpenedo, e Henrique Caetano NARDI, 2008, “Diversidade sexual e trabalho: reinvenções do dispositivo”, Bagoaa: Revista de Estudos Gays, 3 (2): 127-144.

RODRIGUES, Raimundo Nina, 1935, O Animismo Fetichista do Negro Baiano. Rio de Janeiro, Civilização Brasileira.

RUBIN, Gayle, 1993, O Tráfico de Mulheres: Notas sobre a "Economia Política" do Sexo. Recife, SOS Corpo.

— 1998, "Thinking sex: notes for a radical theory of the politics of sexuality", em Peter Nardi e Beth Schneider (orgs.), Social Perspectives in Lesbian and Gay Studies: A Reader. Londres, Routledge, 100-132.

SANTOS, Josélio, 2002, "Menininha do Gantois: a sacralização do poder", em Vagner Gonçalves da Silva (org.), Caminhos da Alma: Memória Afro-Brasileira. São Paulo, Selo Negro, 133-152.

SEGATO, Rita, 1995, Santos e Daimones. Brasília, Editora da UNB.

TEIXEIRA, Maria Lina, 1987, "Lorogun: identidades sexuais e poder no candomblé", em

Marcondes Moura (org.), Candomblé, Desvendando Identidades. Rio de Janeiro, EMW, 33-52.

WEBER, Max, 1989, "A objetividade do conhecimento nas ciências sociais", em G. Conh (org), Weber. São Paulo, Ática, 79-127. 